paratively tender foliage. Where similar conditions which they eat, not only will a great deal of leaf perfora- FREAKS, AS PERTAINING TO DISEASES OF prevail in Washington and its vicinity, a third genera- tion by the beetles themselves be prevented, but the tion of larva may develop, though small in numbers, number of eggs laid will be very greatly lessened. bate developing beetles of the first generation may
lasis is directed against the larvæ, the majority o hibernate. Remedies. - The only thoroughly satisfactory safe- after. A third spraying, and even a fourth, or under
exceptional circumstances a fifth, may be reguired if it guard against this insect consists in spraying the trees exceptional circumstances a fifth, may be required if it with an arsenical solution. The only other remedy which is considered neessary to keep the trees fresh and
is worthy of mention is the destruction of the larva at
green, and particularly if the earlier sprayings have to pupz. The latter remedy, however, is not complete, and even where it is carefully carried out for every tree in a city, it will do no more than reduce the numbers of the insects by perhaps two-thirds. Ten years ago a proposal to spray the enornous elms of all the trees in a given precinet will probabily be as
which are to be found in many No thern towns would
much as will be required, especially if this be done have been received with ridicule, but of recent years
the practicability of the plan has so frequently been de-
yof the larv year and some pains be taken to destroy such
thecessfully develop and descend the practicability of the plan has so frequently been de-- of the larvæ as may successfully develop and descend
monstrated that there is no hesitancy in commending it
for transformation. Even two sprayings, covering all to more general city use. Probably the largest elm tree the elms of a city or town, will be well worth the exin America, the Dexter elm, at Medford, Mass., has been sucessfully and economically sprayed by the Gypsy Moth Commission. It is necessary to have especial ap. may substance to be used in these spraying operation paratus constr cted, and it is equally necessary to have lead. The directions for the use of these substance loest ark done by men who are accustomed to it or at least are good climbers. The first sucessful work of
this kind was probably that done by Prof. John $\mathbf{B}$. the been so often repeated that is not worth whil

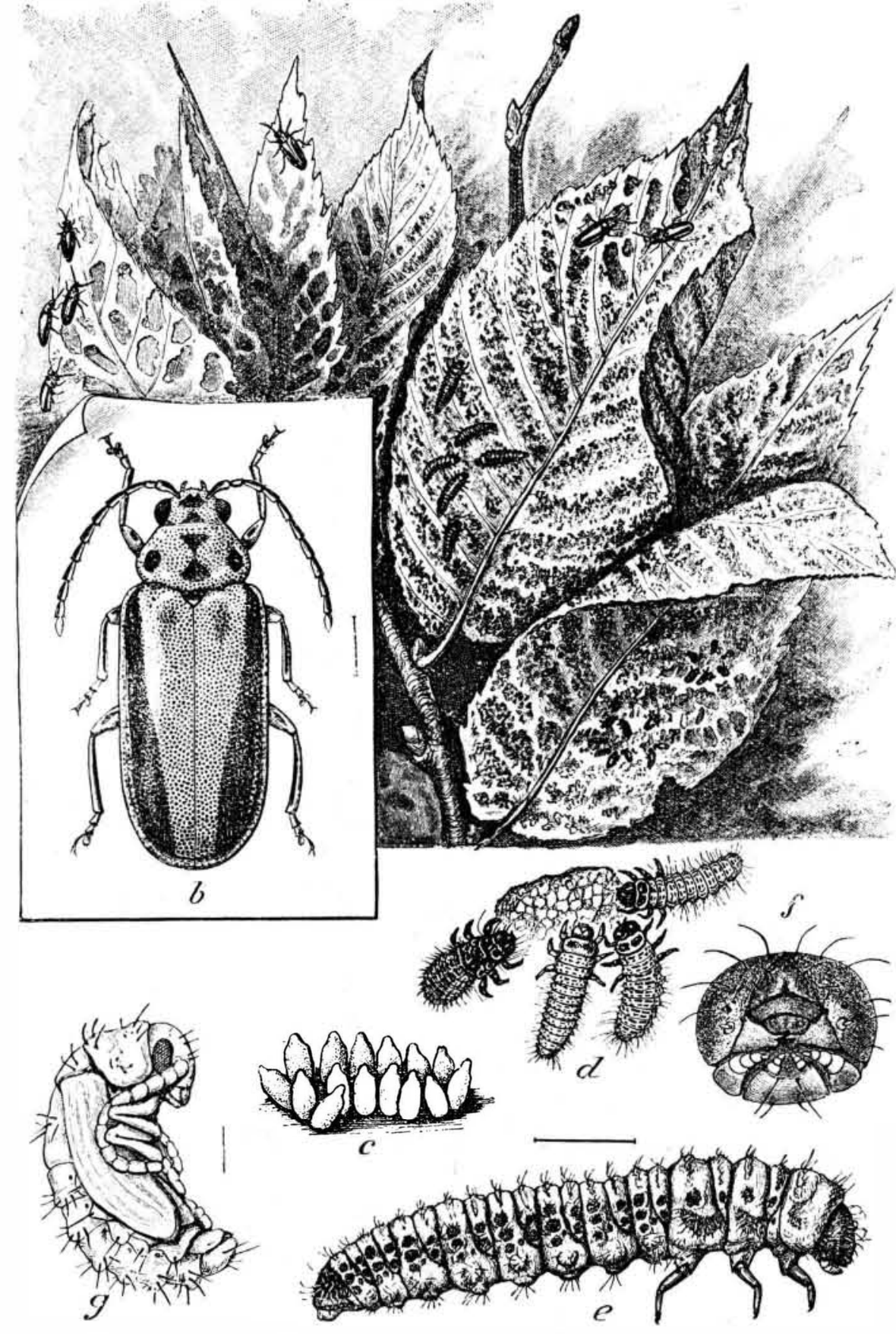

Fra. 3.-The Imported Elm Leaf Beetle (Galerucella luteola). a, foliage of European elm, showing method of work of betle and larva-natu al size ; b, adult beetle c, egg mass; d, young larva; e, full grown larva : g, pupa-all gro
f, mouth parts of full grown larva-still more enlarged (original).

strong ba rel pump, and carried the nozzle at the end must always be, incomplete. The standard kerosene of a long rubber tube, with a bamboo extension pole, emulsion, diluted one part to five pa ts of water, will up inain crotch. From this point the spray was thrown in all directions, and the tree was thoroughly coated the past season, particularly in New Haven. It must The mixture in a minimum of time.

The Gypsy Moth Commission, in their earlier spraystopping at each tree and sending one or more met with hose and extension poles into it, thus covering hundreds of large trees in a single day. If steam sprayers are used (and the town or city fire engines can be and have been used to excellent advantage in this way), the necessity for climbing the trees may be largely
avoided. By means of multiple discharge hose both sides of a tree, or even of two trees, may be sprayed at a day is surprising. The elm trees in a small park may be treated econonfically and without much difficulty by two or three men with a handcart tank. This method
has been adopted on the large grounds of the Department of Agriculture, with absolute success.
The writer's experience at Washington leads to the conclusion that it is important to spray trees once just

af these beetles can be destroyed by poisoning the leaves. e applied to the base of the trunk and under the entire moved to a slight extent (the writer does not advocate which scraping), leaving as few crevices as possible ery large, it will pay occasionally to climb into the main crotch and destroy such individuals as may have collected at that point. Experience leads us to estithirds of the larve reach the base of the tr nk and drop from overhanging branches has been questioned and it is sometimes a difficult matter to decide. The attention to a peculiar and eminently satisfactory case
where the drooping branches of a la ge elm extended completely over a house, on the other side of which beneath the tips of the overhanging branches, the larve

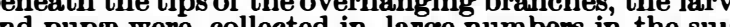
mer of 1895 .

(To be continued.)
THE SKIN.*

By James C. McGuire, M.D., Washington, D. C.

IT is not alone in post graduate schools and hospitals we should look for clinical material ; the dime museum excellent advantages for instr ction. Especially is this true as regards skin diseases. Many anomalous examples of cutaneous lesions, that would be difficult to find as a r le, the disfiguring lesions have not been treated in any way more likely still are they to have been interest to they are in full bloon. It may be of rom a scientific standpoint-to properly classify them The popular names given to many of these deformities are given them on account of their resemblance to "elephant man," "elephant leg," the "fish-skin girl," the "dog-face boy," the "leopard boy," etc. Other lady," the "blood sweater," the "albinos," the" man with horns," the "blue man," etc. " cupine man" the "hedgehog man," all suffer from different manifestations of the same disease. The appearance of the skin so closely resembles that of fishes
it is designated as ichthyosis ; it is a congenital chronic disease, characterized by dryness, harshness, and scaling usually showing itself within twelve or sixteen month there is only slight scaling, but the natural furrows of the cuticle are much exaorerated In some pronounced cases, the skin is divided into diamond shaped figures, and scales appear in abundance-white or dark green in color-and are especially adherent in the center,
These are the cases to which the terms "fish skin," "snake skin," are applied.

In the most severe manifestations of the disease designated as ichthyosis hystrix, the hypertrophied resembling the bark of a tree rather than fish scales. There may be spinous or quilled excrescences, as in those
cases designated as "porcupine men," "hedgehog A very remarkable case of ichthyosis hystrix was shown at the Royal Society, March 16, 1731, reported years of age. "His skin (if it might be so called) seemed rather like a dusky colored thick case, exactly fitting every part of his body, made of rugged bark or hide, with bristles in some places. It did not bleed when cut or scarified, being callous and insensible. It was said
he shed it once a year. It is not easy to think of any sort of skin that exactly resembled it ; some compare seal skin; others like the hide of an elephant. The bristly parts, which were chiefly about the belly and flanks, looked and $r$ stled like the bristles or quills of a hedgehog, shorn off within an inch of the skin. The patient was again shown twenty-four years later formity. He had had six children, all of them presenting exactly the same delority. may be propagated by this man having such rugged coats or coverings as himself.'

Dr. G. H. Fox reports $\ddagger$ an interesting case of ichthyosis-the "alligator boy." The article is accompanied with two excellent colored plates. as ichthyosis congenita. Some authorities - Hebra, Kaposi, and others-regard it as a distinct affection, conIt is said to begin at an early period of intra-uterine life. At birth, the skin appears too tight, for the body is deeply fissured and hypertrophied, resembling plates of armor; to this form of the disease the term harlequin foetus has been applied.
One of the most conmon of the freak family is the albino, a name given to those who suffer from a par-
tial or complete loss of pigment, of congenital origin: it is said to be seldem met with in the white race; not thecutaneous covering as well examples of albinismus. The "leopard girl" is affected with leucoderma, a word
derived from the Greek, meaning white skin; the term derived from the Greek, meaning white skin; the term
vitiligo-a blemish-is also applied to the deformity. It differs from albinismus from the fact that it and not congenital. The loss of pigment occurs in till the whole skin is affected the hairs on the affected patches also turn white. As to causation, it is said to be due to "disturbance of innervation." Many cases have been on exhibition; and it is not unusual to see it on the hands and face of negroes in this city. In the mulatto who became perfectly white, except a patch on the chin.

Leucoderma also affects the lower animals, as in the case of the "sacred white elephant." They are not re-
ally white, but of a pale flesh color. We will not look upon these sacred animals with such reverence when we learn the condition may be produced by artificial means. Dr. Piffard has witnessed the experiment of
bleaching the skin of the ordinary elephant, by means of peroxide of hydrogen; it was applied several times a light ash color, but he did not believe it would be permanent. have been several elastic skin men on exhibition; the best known of them is Herr Hagg, who could pull the skin from his chest up to his eyes. Meekren, the skin of his chest up to his eyes and down to his the skin of his chest up to his eyes and down to his
knees. These cases are a form of dermatolysis, a rare deformity, that is owing to some defect in the attachment of the cuticle. It is a congenital affection, though it is said the ability to move the skin is increased by * Read before the Medical Society of che District of Columbia, Febra-
ary 19,1896 .

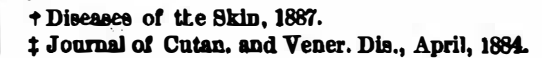


abnormal growth of skin, attended with thickening; so much. Some years ago, a lady, living in New York, the integument hangs in folds and overlapping layers. stated to me that the dark ring about her wrist was An excellent example of this is seen in plate No. 7, an caused in this way. While she and her family were
Harlingen's Handbook of Skin Diseases. All of the sitting at the dinner table, during a severe thunder
above cases have several peculiarities in common; the storm, the window being open "a ball of fire entered deformities are not amenable to treatment; the general ; and knocked us all senseless; it was some time before I health is, as a rule, not affected, and practically no"The "bluct of inh" may tendency.

"The "blue man" may be suffering from a condition "bluish discoloration of the skin from defective aeration of the blood, either temporary, as in asphyxia, or perthe heart, especially persistent patency of the foramen ovale; or the blue man's condition may have been
brought about by the ingestion of nitrate of silver." An extremely interesting case, occurring without aslas of Rare Skin Diseases). The patient was a harness maker, 49 years of age; the condition affects the body
generally. He suffers from intermittent pains of burngenerally. He suffers rom intermittent pains of burn-
ing, shooting chiarater, chiefly in the epigastrium and
left lumbar region. I Pains and discoloration comleft lumbar region. I Pains and discoloration comhospital, and though under observation for three the patient's occupation to account for the discoloraA few years ago a man exhibited himself in a New
York museum, with a horn growing from his forehead; it resembled an animal's horn in respect to shape and size, but was of a dark grayish color, and rough and harsh to the feel. This condition, known as cornu cu-
taneum, may occur on any part of the body and be of any shape and number; they differ from similar ap
pentages in cattle, from the fact that, in these animals,
the horn grows only from osseous tissue. There is a specimen in the British Museum that is said to measure
11 in. in length by $2 \frac{1}{2}$ in circumference. Lebert, in 1864 , reports 109 cases he had compiled from different
sources; in 12 per cent. of these cases it gave rise to consources; in 12 per cent. of these cases it gave rise to con-
secutive epithelioma. "Elephant leg," "Barbadoes leg," is the well known "hypertrophy of the cutis and subcutaneous cellular tissue, which is confined to some region of the body,
due to local circulatory disturbances." The most frequent seat of the disturbance is the lower extremity;
rarely are both limbs affected. At first there is a deep seated inflammation that leaves the parts in a swollen edematous condition. Every few months this is repeatenormous proportions as even to interfere with locomoenormous proportions as even to interfere with locomo-
tion; the surface unay be smooth or warty; sometimes
the bones are affected. An interesting case allied to this disease is described
in the British Medical Journal December 11, 1886, under in the British Medical Journal, December 11, 1886, under case of congenital deformity of the skin and bone. The
bony exostosis on his frontal bone, combined with a deformity on the superior maxilla, gives a trunk-like ap-
pearance to the nose and upper lip, the profile of the pearance suggesting the profile of an elephant's head. "The tissue is very loose, so that it can be raised from the
deeper parts in great folds. The cranial bones are deformed and overgrown, so that the circumference of the patient's head equals that of his waist. Bony exostoses
spring from the frontal bone, the posterior part of the parietals and the occipital." The patient can give no
family history of similar deformity, but declares his mother was knocked down by an elephant when bearing him. The papillary excrescences are increasing right hand is causing it to become slowly crippled ; general health good.

chronic inflammatory disease, characterized by a hardening and rigidity of the cuticle over areas of greater or less extent ; the surface may be white, yellowish, or
even bronze color ; the skin may become shrunken and depressed ; when limited in extent it is known as morphea, though some authorities consider the latter an There are of the nervous system."

There are some anomalous conditions of the integrn-
ment which may not be out of place to refer to in this ment which may not be out of place to refer to in this
article; though, as a rule, the subjects do not exhibit themselves, they are none the less interesting. In my personal experience, I knew of a young woman, in exhaled an odor so much like violets it had been remarked upon; in consequence, she is in the habit of flower about her person. The odor is always accom-
panied with excessive sweating ; the perspiration is so expansive she willsoil several pairs of gloves during an evenmidrosis (stinking sweat), but in this case a better namis osmidrosis.

Colored sweat, known as chromidrosis, is usually
feigned, but there have been a few well authenticated cases reported. The condition may be due to the growth of micro-organisms; it may also be caused by
the medicine the patient is taking, as in Dr. Taylor's iodide of potash. The condition is supposed to have been brought about by the reaction of the iodine in Occasionally we read in newspapers of hysterical is known as hæmatidroses. Kaposi declares this is not traumatic exit of arterial blood from the pores of the
skin." In his work on "Diseases of the Skin" he refers to a case observed by Hebra, who once saw a spiral stream of blood spurt from the opening of a sweat gland phosphorescent sweat have been recorded, though it is
said to be caused by fish diet. S. Pollitzer considers it not unlikely that the phosphorescence is due to action of phosphoric bacilli, many varieties of which have been
described. tion those cases in which objects, such as trees, are indelibly infpressed upon the skin of those who have been struck by lightning: Prof. Wright, of Yale University,
declares that these images are photographed by means of the chat these images are photographed by means for 1831. The
My hair is gray, though not with years, In a grew it white night,

History records, but on doubtful authority, that the
hair of Sir Thomas Moore and Marie Antoinette turned suddenly white the night before their execution; that
Henry of Navarre was so shocked on hearing that the edict of Nemours was conceded, the hair of his moustache whitened in the course of a few hours.
have been mont accept these cases as authentic, there competent observers; so that sudden blanching of the hair under great mental enotion is considered a possible i have consulted except Prof. Ka all authori, of Verina. He declares that though grayness of the hair may occur in a
short time, he does not believe it can occur suddenly short time, he does not believe it can occur suddenly son and others declare the condition is due to the formation of air bubbles between the hair cells of the corcolor substance; the air renders it opaque, so that the
coment is obscured. Kaposi's views do color of the pigment is obscured. Kaposi's views do
not coincide with these ; he believes grayness is due to loss of pigment, and does not consider the influence of velop in the hair, and that these gases or air conceal

Notwithstanding the negative views expressed by
such an excellent authority as Prof. Kaposi, that sudden blanching may occur has been proven beyond a Sir Erasmus Wilson mentions the experiments of Sir
John Ross. He exposed a lemming-a kind of rat-to John Ross. He exposed a lemming-a kind of rat-to ero; the next morning the fur of the cheeks and spots
upon each shoulder had become white; within a week the back.

There has recently been reported a case the reve
canities, where gray hair suddernly became black.
There is also a rare condition of the hair in

There is also a rare condition of the hair in which natural color. In the Londen Lancet, 1881, Squire
gives an account of a boy sixteen years old, one side of whose head was piebald like a tortoiseshell cat, th 政

As has already been said, loss of pigments may occur
elsewhere than on the skin and hair. The nails of the Dr. S. Giovaninni, in the International Atlas of Rare Skin Diseases, describes a case of this kind, which he
calls canities unguium. An abbreviated report of the case is as follows: Coachman, 29 years of age : all the otherwise normal; the condition first occurred during
convalescence from typhoid fever, when twelve years old ; the second and third toes of each foot are webbed
(syndactylia), otherwise the patient is well formed and in good health. The condition is supposed to be due to penetration of air into the interior of the nails, prac-
tically the same condition that occurs in canities.
Dr. G. P Unna has reported a second case in the same Dr. G. P. Unna has reported a second case in the same
Atlas. To it he has applied the name of leuconcychia, preferring it to the term canities, which he thinks patient, twenty-six years of age, at first noticed the eon-
dition when a child. In this case the hair is also affected. The pathological changes consist in dryness and The "bearded women" that grace so many of the museums by their presence must not be left out of this deformity rather than a disease, known as hypertricho-
sis, or hirsuties, which simply means a growth of hair absis, or hirsuties, which simply means a growth of hair abare normally found. Chowns speaks of a boy eight years
of age who had the whiskers of a man. Dr: Cummins mentions the case of a lady who was noted for the
beauty of her face, whose body, from breast to knee was covered with a profusion of black, thick, bristly
hair. These cases and others are referred to in Dr. Jackson's Diseases of the Skin. He says partial con-
genital hypertrichosis is apt to be of the nature of The distinction between the localized hypertrichosi and nævus is mostly made upon the color of the under-
lying skin. In the former case the skin is perfectly normal, while in the latter it is pigmented, and may be otherwise altered. of Diseases of the Skin, is the best known specimen of
homines pilosi. Exactly the opposite condition is the universal loss of hair, known as alopecia universalis. Inatology. January, 1896, reports a case of this kind.
All the huirs of the body were lost, even the fine downy ones known as lanugo hairs. The process was slow and
insidious. He says: "As thoroughly a naked indi-
vidual as could be imagined is a result of the effect of this universal process." probably the most unique of all. It is known as phagmesis, in which feathers adorn the body instead of hair.
Dr. G. T. Jackson, in his most excellent treatise on owing statement: "Dr. T. Robinson cites a case of this nature which occurred in a boy who was exhibited at with feathers in place of hair."-Va.Med. Semi-Monthly.
As men's have grown from sudden fears." une animal was perfectly white except a small patch on

SELECTED FORMULAE.

Restoring German Gilt.-The following varnish is use-
lor fortoring tarnished German gilt picture frame moulding :

Gamboge

30 grains.

Powder the above and then add

Turmeric.

$\stackrel{30}{21 / 2}$ ounces.

Sace the whole of the above in a bottle, and add two Place the whole of the above in a bottle, and add two
ounces dry oil of turpentine; shake often, keeping in a ounces clear mastic varnish as above. - Canadian
Pharmacist.

Remedy for Codlin Moth on Apple Trees.-One pound Paris green, one ponnd lime, 250 gallons of water; or,

A Matt Black for Iron.-According to the Revue un be obtained by the a use of the following solution:

Mercuric chloride................. 2 parts.

Cupric chloride....

Alcohol 6 part.

The article is carefully cleaned and immersed in the which or a brush may be used for its application, after application can be given if the color is not dark enough.
and

Nail Cleaning Liquid.-
Tartaric acid ...
Tincture myrrh
1 drachm.
drachms.

Dissolve the acid in the water; mix the tincture of myrrh and eau de Cologne, and add to the acid solu-
with a chamois pad.

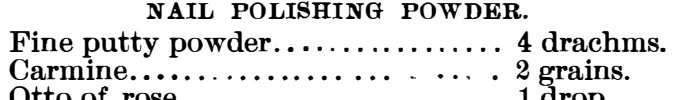

Very carefully reduce the carmine with the putty powder, and rub together until a homogeneous mixture amped, and a little of the powder put on ; then polish a chamois pad.-Bulletin of Pharmacy.

Oxidizing and Blacking Bright Steelwork.-The followor direction for oxidizing and blacking the bright well, is taken from a recent issue of the English Mechanic : "Take three ounces of glacial acetic acid, mix
it with its weight of water; to this add half an ounce of powdered nut, galls, and let stand for a day or two,
shaking it up occasionally; then let settis, then pour off the clear, then put a pint of water to the resi-
due. When cold and settled, pour off the clear and mix with the first. Now to this add a grain of ni-
trate of silver, or sulphate of copper or nitrate of copper. Dissolve whichever you use in a little ho is the best process. Clean all oil off and rust or stone powder. Don't use emery in any form, but the above with a piece of wood. Then clean all off ; dry with some cotton wool. If you have saved your pow-
dered galls, take a little of that upon your wool, and you will find that a great acquisition in the first appli-
cation. Let stand until dry, then give it another coat. When dry, scratch, brush it, and give it another coat etc. When you have got it to your liking give it some
linseed oil and camphor. All bright iron parts can be made like ebony polished, and with the gun-metal mounting you will have a picture in black and gold
Cylinder covers, etc., can be done the same; but you must wash with hot water before oiling it. It will stand any amount of heat, the hammer and friction in wip-
ing; you have no blistering, and you will have some difficulty in eradicating it. Bicycles, repairs, handle bars, etc., can be treated the same way to advantage,
well washed with hot water; when dry give them a coat " carriage varnish."

Cement for Porcelain. - 1. To cement porcelain to alcohol ( 95 per cent. strength), and use this fuid to make a paste with ten ounces finely powdered chalk and eight ounces starch. Then mix in three ounces of
Venice turpentine. 2. An excellent cement for china and porcelain may be obtained by melting togethe seventy-five grains of fish-glue and five drachms of until it becomes of a sirupy consistence, so as to form a jelly upon cooling. To use it, the jelly is placed upon the edges of the broken crockery are coated with it, and the pieces strongly compressed. 3. A cement for fixing
enamel plaques to nickel is prepared by dissolving to-
gether by a gentle heat:
Gum damar
Venice turpentine.
10 parts.
Ultramarine.
quantities to tint the mass.

The coloring matter (zinc white and ultramarine) is rendered fluid. This cement should be used hot, and
rented the compound when the solids have been when cold can be polished. It is also suitable as a
putty for filling up cracks in enameled surfaces.-

\section{Glycerin Suppositories.-}

Lanolin....

Cacao butte

30 grains.

White wax.

Melt the ingredients together, stirring well, and pour 